\title{
Analysis of innovation system and technology transfer
}

\author{
Tatyana Maximova, and Nada Eid $^{*}$ \\ ITMO University, 19710 Saint Petersburg, Russia
}

\begin{abstract}
The importance of scientific research and technological development is reflected in the fact that it is a fundamental contributor to meeting the needs of the industrial and economic sectors, creating job opportunities, and enhancing revenues by employing its outputs, in addition to its effective role in community building, development and welfare. In this paper, we have chosen the Syrian Arab Republic as an example for the analysis of the innovation system and technology transfer. We review the status of scientific research and technological development in Syria, since its official inception in 1958 until the present time. We conduct an analysis of strengths, weaknesses, opportunities and threats in the innovation and technology transfer system in Syria (SWOT analysis). In order to reach an integrated system based on scientific research, we present a set of recommendations that help enhance strengths and overcome weaknesses. These recommendations also help to exploit the available opportunities and turn them into strengths, in addition to finding appropriate solutions to the risks faced by the innovation system in Syria.
\end{abstract}

\section{Introduction}

Research and technological development is an innovative, systematic activity aimed at increasing the pool of knowledge and using this reserve to develop modern applications, in addition to its effective role in building a knowledge society and achieving sustainable development [1].

Scientific research officially began in Syria in 1958, when the first law on the organization of universities in the United Arab Republic was passed and the Supreme Council for Science was established [2]. In 1969, a research center was established to conduct research in support of the economic and technological development of Syria. In the 1980s and 1990s, more emphasis was placed on research and development for sustainable development and job creation [3].

In 2005, Decree No. 68 was issued establishing the High Commission for Scientific Research as a public authority of an administrative nature, responsible for the formulation of a comprehensive national policy in the field of scientific research and technological development, as well as for coordination between research bodies and support in achieving their goals at all levels, and for strengthening the mechanisms of communication between

\footnotetext{
${ }^{*}$ Corresponding author: nadaeid1991@hotmail.com
} 
research bodies and parties requesting research in a way that facilitates its funding and marketing [2].

The Commission prepared and published in 2017 the National Science, Technology and Innovation Policy Report, which includes the first national science, technology and innovation policy in Syria. While the implementation of this policy is influenced by the current crisis in the country, it is an opportunity to prove the importance of research and technological development during crises and their role in helping to revive various development sectors [3].

Analyzing the reality of scientific research in Syria, it must be recognized that the activities carried out by scientific, technological and innovative institutions in Syria over the past decades have been below ambition in terms of quantity and quality. Syria's downgrade in terms of innovation can be attributed to many reasons. Some researchers attribute this decline to several reasons, the most important of which is the strategic position of Syria, which made it vulnerable to periodic wars that threaten its security and stability, the most recent of which is the ongoing war, as well as the brain drain and lack of an environment conducive to creativity or suitable for attracting talent. In addition, a large number of successes of some national scientific organizations have not found a suitable environment for their investment, since these organizations differ in their ability to make the most of the human and material resources available for scientific research, due to the complexity of the existing regulations and legislation and their inconsistency with the nature and the requirements of research activities of a scientific and innovative nature [4].

\section{Literature review}

In domestic and foreign scientific literature there is a large number of works devoted to study the national innovation systems.

The theory and practice of the development of national innovation systems and their individual elements, the experience of the formation of NIS in developed countries, the issues of activating and optimizing the innovative activity of the national economy are considered in the studies of B. Lundvall, R. Nelson, C. Freeman, S.D. Valentia, V.I. Kushlin, V.L. Makarov, N.I. Ivanovaya, V.V. Ivanov, K.I, Pletnev, A.N. Folomev, N.V. Shelyubskaya and other economists $[5,6,7,8,9]$.

The development of directions and strategies for the functioning of the domestic NIS, the definition of the role of state policy and other organizational and economic factors in innovation, as well as certain issues of scientific, technical and innovation policy and the need for its improvement are actively discussed in the works of A. Dagayev, L. Drobyshevskaya, A. Dynkin, O. Golichenko, C. Gubanov, G. Kostin, Y. Osipov, A. Rumyantseva, G. Simonia, V. Sokolinsky, R. Fatkhutdinov, P. Shchedrovitsky, E. Yasin and others $[10,11,12,13,14]$.

\section{Aim and objectives}

This work aims to advance the innovation system so that it can take its important role in the development process in the Syrian Arab Republic.

To achieve this goal, the following objectives were identified:

- Analysis of the status of scientific research and technological development in Syria.

- Analysis of strengths and weaknesses, opportunities and threats in the system of innovation and technology transfer.

- Submitting recommendations that help reach an integrated system based on scientific research, which would help improve the innovation climate in Syria. 


\section{Analysis of strengths and weaknesses, opportunities and threats in the system of innovation and technology transfer}

Despite the tremendous efforts being made to promote scientific research, and the great efforts being made by scientists and engineers at universities, research institutes and modern technology centers, the results of the scientific and technological sector remain modest, and the impact of scientific research on the development of the Syrian economy and society remains without real impact [15].

Despite the incompleteness of the system of innovation and technology transfer in Syria, its foundation exists and can be strengthened [15], and in order to achieve the desired goal of achieving an integrated institutional system based on research and technological development, the current reality of this system must be analyzed to enhance its strengths and overcome its weaknesses. It is also important to know the opportunities available to them to invest and turn them into strengths, as well as the risks they face in order to find appropriate solutions for them.

An analysis of the current reality of this system shows the following:

\section{Strengths:}

- Several research organizations that are financially and administratively independent, some of which have modern equipment and qualified research personnel [16].

- The wide spread of public and private educational institutions, the variety of their specializations and their uniqueness in teaching most of the specialties in Arabic, including medical and engineering sciences [16].

- Availability of a number of specialized professors from prestigious universities, since the policy of scientific openness to the outside world has allowed Syrian students to spread to various universities in the world, and their return to their educational institutions has affected the local scientific environment [15].

- A relative increase in the number of affiliates to universities, and a relative decrease in the cost of university education [17].

- Public and private universities have good own resources.

- The presence of a network of Syrian scientists, academics and investors in the countries of expatriation.

- Availability of qualified personnel.

- Good infrastructure in some sectors.

- Availability of some technology incubators in some research and support agencies [17].

\section{Weaknesses:}

- Lack of strategic vision to invest in existing capacity.

- Weak environment for the development of science, technology and innovation.

- Weak coordination between ministries and relevant authorities to create supply and demand in the research sector, as well as weak coordination between research authorities.

- Weak public and private resources for research and technological development.

- Low incomes for research workers compared to neighboring countries.

- Low technical content of the local industrial structure and weak state initiative in the process of technological modernization [18].

- Widening gap and weak trust between the research sector and the economic and social sectors.

- Insufficient interest of private sector institutions in research and technological development.

- Low qualifications and technical backwardness of production institutions, as well as a lack of investment necessary for the development of skills and technologies [19].

- The salary structure is undifferentiated to stimulate skill development, workmanship and innovation. 
- Lack of qualified personnel in many new technical specialties and obsolescence of existing skills.

- Weak banking support for industrial investment and innovation.

- Insufficient support structure for small and medium enterprises.

- Regulations in universities and research centers do not create an enabling environment for innovation.

- Lack of foreign direct investment in science and technology [18].

\section{Opportunities:}

- Young human capital capable of keeping pace with scientific and technological progress.

- The ability to enter new markets based on the comparative advantages of products and their cost while increasing their added value.

- Adoption of the principle of partnership between the public, private and collaborative sectors [20].

- The colossal revolution in communication technology, the flow of information and the building of communication bridges made possible by globalization.

- A promising local market for investments in high technology such as informatics, biotechnology, nanotechnology and energy.

- Existence of a tendency to support scientific research and technological development in universities and other research bodies, linking with productive and service institutions, and encouraging creativity, inventions, competencies and talents.

- Opportunities for international cooperation and opening the way for foreign direct investment [21].

- Creation of institutions based on information and communication technologies.

- Crystallized conviction in the manufacturing and service sectors of the importance of science, technology and innovation and their endeavor to adopt methods of technological upgrade and raise the skills of the workforce [20].

- Syria's entry into the recovery phase and the need for direct scientific broadcasting to service the recovery process [21].

\section{Threats:}

- Failure to embody a real belief in the role of science, technology and innovation in improving an underdeveloped reality with real and effective support for a system of science, technology and innovation.

- Brain drain and competence drain and the desire of skilled workers to emigrate abroad [18].

- Deteriorating regional security situation and continued technology embargo on Syria.

- Slow pace of economic and administrative reforms and lack of common strategies.

- Resistance to change, especially change that requires the use of science and technology in strategic planning [19].

- Failure of ministries and departments to respond to scientific initiatives put forward, especially those that call for the adoption of scientific research and the use of modern technologies.

- Slow development of education and training systems and curricula [18].

- Delay in developing the necessary systems to create an appropriate and stimulating enabling environment for technology transfer and research investment.

- Lack of incentives for the private sector to invest in research.

- Challenges posed by globalization for the manufacturing and service sectors, as well as growing competition from Asian and Eastern European countries as a result of market openness.

- Complex procedures for creating startups [22]. 


\section{Results}

It should be recognized that the activities carried out by the institutions of science, technology and innovation in Syria over the past decades have been much less than the capacity and needs of its people in terms of quantity and quality [16].

The lack of research programs is evident in priority sectors that can have a competitive advantage, such as textiles, food and pharmaceuticals, as opposed to interest in other sectors such as information, communications, environment, construction industry and oil, while the number research projects and programs in the areas of water resources, renewable energy and human capacity building remain relatively small [23].

Most of the problems of the system of science, technology and innovation can be summarized as follows:

- Poor planning and coordination at sectoral and national levels.

- Weak funding for research and low salaries for researchers.

- Research infrastructure is not keeping pace with the rapid development of science and technology.

- Unclear national priorities for technological development and innovation in the country.

- Decrease in the results of scientific research in quantitative and qualitative terms.

- Most of the research carried out has no applied or developmental impact.

- Small patent registration.

- Lack of high-quality research results suitable for patent protection.

- Fragmentation of the national innovation system.

- Lack of coordination and communication between stakeholders from the private sector and educational and research institutions, as well as weak interaction between them.

- Lack of serious demand for R\&D due to weak linkages with manufacturing and service sectors and low confidence in their importance.

- Weak return on research and innovation.

- Flooding universities with an educational position at the expense of research work.

- Individual inclination to conduct research and lack of formation of integrated research teams.

- Low awareness of researchers and their institutions, and of the management of intellectual property protection objectives.

\section{Recommendations}

1. Make scientific research and technological development the highest priority so that material, human and legal resources are used to advance them.

2. Encouraging and facilitating the creation and reform of scientific and technical institutions and periodic analysis of their activities and the achievement of desired goals.

3. Creation of elite institutes and technological institutes as a future goal in parallel with existing universities and institutes and revision of approved curricula at all stages with the aim of increasing scientific and technical disciplines in them and introducing materials related to production, quality, standards and information technology and other new materials in the global economy.

4. Focusing on building technological capabilities in specific areas in accordance with the studied priorities and promoting new research directions in the field of renewable energy research, biotechnology, nanotechnology, new materials, biological drugs, immunological research and others.

5. Encouraging work on reverse engineering for technology localization.

6. The introduction of scientific research subject in university education. 
7. Acceptance of the idea of lifelong learning, especially in rapidly developing technological areas, and gradually increase funding for this learning.

8. Coordination and communication between research and technological institutions, production activities and services, intermediary institutions linking research and development, on the one hand, with production and services, on the other, scientific and publishing institutions, information networks and their rules, scientific and technological societies, scientific and technical societies, institutes of standards, metrology and quality, as well as institutes of accreditation.

9. Increasing funding for research and improving the status of science and technology workers to stop the brain drain and, if possible, bring some of them back.

10. Modernization of the administrative and financial system of research organizations in order to make it more flexible and include an appropriate mechanism to provide incentives for research workers.

11. Establishing a compensation policy for outstanding applied research and registered industrial patents.

12. Adopting a policy linking graduate projects and $\mathrm{PhD}$ dissertations to industrial and social issues.

13. Establishing intellectual property policies in universities and research centers, as well as establishing rules for the ownership of research results, setting up dedicated technology transfer offices, focusing on technology transfer contracts, and enacting policies and legislation that allow universities, research centers and their staff to establish and manage technology companies based on the results of their research and protect their private rights.

14. Restructuring of the intellectual property protection system and the national innovation system, unification of its components and organization of its connection with technology transfer offices in universities and research centers, if they are created.

15. Adoption of policies and legislation that support research in private sector companies, including tax legislation that encourages research and development, and takes into account research and development costs, innovation patents and exports.

16. Encouraging the private sector to invest in scientific research and establishing a national innovation fund, to be financed by the private sector.

17. Encouraging donors to support research and their staff.

\section{Conclusion}

The development of a national science, technology and innovation system and its successful fulfillment of tasks in support of development requires sound policies, an enabling environment, adequate funding and a constant supply of highly qualified human capital.

The research described in this paper is partially supported by the ITMO University Research program (№ 619403).

\section{References}

1. A. Dagaev, State guarantees for small innovative business // Management in Russia and abroad, No. 4, Pp. 81-88 (2006) (rus).

2. B. Abassi, The determinants of innovation: An empirical analysis in Egypt, Jordan, Syria and Turkey, Canadian journal of development studies, No. 35(4), Pp. 560-578 (2014).

3. Syrian Arab Republic, Presidency of the Council of Ministers, The National Development Program for "Syria After the Crisis", Damascus. URL: http://pministry.gov.sy/ (2017) (arab). 
4. E. Abdou, and others, Social Entrepreneurship in the Middle East Toward Sustainable Development for the Next Generation. Massachusetts: Wolfensohn Center for Development at Brookings; Dubai: Dubai School of Government; Doha: Silatech (2016).

5. B. A. Lundvall, National Systems of Innovation. Towards a Theory of Innovation and Interactive Learning, London: Pinter Publishers (1992).

6. R. ed. Nelson, National Innovation Systems: A Comparative Analysis, N.Y.: Oxford University Press (1993).

7. C. Freeman, Technology Policy and Economic Performance: Lessons from Japan, London: Frances Pinter (1987).

8. V.V. Ivanov, Formation of innovative systems in the conditions of transformation of the economies of Russia // Dissertations. on the competition account. degree doc. econom. sciences. Moscow: Russian Academy of State Service under the President of the Russian Federation, 350 p (2003) (rus).

9. N.V. Shelyubskaya, The choice of priorities for innovative development in the EU and the prospects for the use of "Foresight" in Russia, Innovations, No. 10 (97), Pp. 52-58 (2006) (rus).

10. A. Dagaev, Evaluation of the effectiveness of R\&D in the knowledge economy // Problems of theory and practice of management, No. 5, Pp. 120-126 (2005) (rus).

11. L.I. Drobyshevskaya, Conceptual foundations of innovation and investment policy in the context of the transformation of the economic system. Krasnodar, 316 p (2005) (rus).

12. A.A. Dynkin, Innovative economy in Russia and in the world / report on the website of the Unity for Russia Foundation, February (2004) (rus).

13. O.G. Golichenko, Science and innovation in the national innovation system of Russia // RER., No. 10, Pp. 12-23 (2005) (rus).

14. A.A. Rumyantsev, Development of organizational and economic relations in the innovation sphere of the region. / A.A. Rumyantsev // Innovations, No. 5, Pp. 32-39 (2003) (rus).

15. M. Al-Kafri, Characteristics of the Syrian economy and development experience, Damask, 190 p. (2019) (arab).

16. The official site of the Ministry of Economy of Syria [Electronic resource] - URL: http://syrecon.gov.sy.

17. The official site of the Syrian Investment Agency [Electronic resource] - URL: www.sia.gov.sy.

18. T. Chahine, Social entrepreneurship in the Arab world - where we've been, where we're going, and what it means for the rest of the world? [Electronic resource] URL: https://pcdnetwork.org (2017).

19. A. Tawfik, Investing in the money market, Damascus, 232 p. (2019) (arab).

20. S. Halabi, S. Kheir, and P. Cochrane, Social Enterprise Development in the Middle East and North Africa: a Qualitative Analysis of Lebanon, Jordan, Egypt and Occupied Palestine. Cairo and Beirut: Wamada (2017).

21. R. Khalaf, O. Ramadan, and F. Stolleis, Activism in Difficult Times: Civil Society Groups in Syria 2011-2014. Berlin: Badael Project; Friedrich-Ebert-Stiftung (2014).

22. The official site of United Nations Population Fund [Electronic resource] - URL: https://www.unfpa.org.

23. P.V. Gusterin, Cities of the Arab East. - M.: East - West, 352 p. (2007) (rus). 